\title{
Extrato aquoso e óleo essencial de gengibre induzem mecanismos bioquímicos de defesa em feijoeiro
}

\author{
Ana Paula Costa ${ }^{1}$, Gabriela Silva Moura1, Jéssica Tais Gebauer ${ }^{1}$, Gilmar Franzener ${ }^{1}$ \\ ${ }^{1}$ Universidade Federal da Fronteira Sul, Campus Laranjeiras do Sul, Paraná, Brasil. E-mail: anapaulacosta23@hotmail.com, \\ bismoura@hotmail.com,jeh_tais23@hotmail.com, gilmar.franzener@uffs.edu.br
}

Recebido: 26/05/2018; Aceito: 31/01/2019.

\section{RESUMO}

Derivados de algumas plantas medicinais apresentam potencial no controle alternativo de doenças de plantas, mas ainda há necessidade de maior compreensão sobre os mecanismos envolvidos. O objetivo desse trabalho foi avaliar a indução de mecanismos bioquímicos de defesa em feijoeiro (Phaseolus vulgaris) pelo extrato aquoso (EA) e óleo essencial (OE) de gengibre (Zingiber officinale). Foram avaliadas a atividade de peroxidases e polifenoloxidases em folhas de plântulas e plantas de feijoeiro das variedades Preto Tuiuiu e Carioca Pérola. Em plântulas, avaliou-se concentrações de $\mathrm{OE}(0,0,1,0,5$ e $1 \%)$ e EA $(0,1,5$ e $10 \%)$. Em plantas, foram avaliadas concentrações de OE $(0,1 \%$ e $1 \%)$ e EA (1\% e $10 \%)$ em folhas tratadas e não tratadas. Também foi avaliada a indução da fitoalexina faseolina em hipocótilos de feijoeiro. O OE e o EA promoveram indução de peroxidases com pontos de máxima entre 57 e 72 horas após o tratamento. Somente o OE promoveu indução de polifenoloxidases. Não foi observado efeito sistêmico em plantas de feijoeiro, mas em hipocótilos houve efeito linear na indução de faseolina. Houve efeito diferencial entre as variedades de feijoeiro utilizadas para alguns atributos avaliados. Os resultados indicam efeito indutor de mecanismos bioquímicos de defesa em feijoeiro pelo OE e EA de gengibre.

Palavras-chave: fitoalexinas, polifenoloxidases, peroxidases.

\section{Aquosous extract and essential oil of ginger induce biochemical defense mechanisms in bean}

\begin{abstract}
Derived from some medicinal plants has shown potential in the alternative control of plant diseases but there is still a need for greater understanding about the mechanisms involved. The objective of this work was to evaluate the induction of biochemical defense mechanisms in common bean (Phaseolus vulgaris) by aqueous extract (AE) and essential oil (EO) ginger (Zingiber officinale). The activity of peroxidases and polyphenoloxidases in leaves of seedlings and bean plants of the varieties Preto Tuiuiu and Carioca Pérola. Concentrations of EO $(0,0.1,0.5$ and $1 \%)$ and $\mathrm{AE}(0,1,5$ and $10 \%)$ were evaluated in seedlings. Concentrations of $\mathrm{EO}(0.1 \%$ and $1 \%)$ and $\mathrm{AE}(1 \%$ and $10 \%)$ were evaluated in treated and untreated leaves. The induction of phytoalexin phaseolin in bean hypocotyls was also evaluated. $\mathrm{EO}$ and $\mathrm{AE}$ promoted induction of peroxidases with maximum points between 57 and 72 hours after treatment. Only EO promoted induction of polyphenoloxidases. No systemic effect was observed in common bean plants, but in hypocotyls there was a linear effect on phaseolin induction. There was a differential effect among bean varieties used for some evaluated attributes. The results indicate the inducing effect of biochemical defense mechanisms in common bean by $\mathrm{EO}$ and ginger $\mathrm{AE}$.
\end{abstract}

Keywords: phytoalexin, polyphenoloxidases, peroxidases. 


\section{Introdução}

A busca por métodos e produtos mais sustentáveis, de menor impacto ambiental e à saúde humana, tem contribuído para o avanço de pesquisas no controle alternativo em fitossanidade. Nesse sentido, tem obtido destaque o uso de derivados de plantas medicinais, tais como óleos essenciais e extratos no controle de doenças de plantas (Schwan-Estrada, 2009). A grande diversidade de substâncias importantes originárias do metabolismo secundário das plantas medicinais tem motivado esses estudos, com resultados promissores (Moura et al., 2014).

Os metabólitos primários das plantas são compostos químicos que atuam diretamente na sobrevivência das células; já os metabólitos secundários são compostos formados na planta a partir de estresses sofridos, servindo como uma vantagem evolucionária para a sua sobrevivência e reprodução, podendo atuar também como pesticidas naturais de defesa contra herbívoros ou microrganismos patogênicos. São derivados diretamente dos metabólitos primários, apresentam estrutura complexa, sendo encontrados em determinados grupos de plantas. Podem ainda ter papel específico nas plantas, como atrativo para polinizadores, adaptações químicas ao ambiente e defesa contra microrganismos (Raven et al., 2014).

A utilização de plantas medicinais tornou-se um recurso terapêutico alternativo de grande aceitação pela população e vem crescendo junto à comunidade médica. São comercialmente importantes para as indústrias farmacêuticas, agronômicas, alimentícias, sanitárias, cosméticas, de perfumes, e muitos constituintes podem ser empregados para diversas finalidades (Bizzo et al., 2009).

Entre os derivados do metabolismo secundário, os óleos essenciais constituem um dos mais importantes grupos de matérias-primas para as indústrias de alimentos, farmacêutica, perfumaria e afins. São constituídos por uma mistura complexa de diversas classes de substâncias (Morais, 2009). A atividade biológica dos compostos secundários presentes nos extratos ou óleos essenciais tem merecido maior atenção nas pesquisas voltadas à proteção de plantas em anos mais recentes (Ootani et al., 2013; Schwan-Estrada, 2009).

Compostos secundários presentes em plantas medicinais podem desempenhar funções importantes em interações planta-patógeno através da ação antimicrobiana direta, ou ativando mecanismos de defesa das plantas que venham a ser tratadas com estes compostos (Franzener et al., 2018; Rodrigues e SchwanEstrada, 2007). Entre os mecanismos de defesa vegetal que podem ser induzidos por princípios ativos de plantas estão as fitoalexinas e enzimas relacionadas à defesa vegetal (Oliveira et al., 2016). As fitoalexinas são compostos antimicrobianos de baixo peso molecular. Entre as enzimas, as peroxidases atuam no processo de lignificação das células vegetais (Sbalcheiro et al., 2009), sendo essenciais para a formação da lignina, a qual pode afetar o desenvolvimento fúngico, seja através de bloqueio físico, tornando as paredes celulares mais resistentes à penetração mecânica, seja pela redução da difusão de nutrientes para o fungo, bem como de toxinas e enzimas fúngicas para a planta (Rodrigues e Schwan-Estrada, 2007). As polifenoloxidases também estão associadas a respostas de defesa das plantas, sendo geralmente elevadas em tecidos infectados. Tanto as peroxidases como as polifenoloxidases lideram a degradação oxidativa de compostos fenólicos como mecanismo de defesa (Barros et al., 2010).

Uma das espécies de plantas medicinais que tem demonstrado promissor efeito no controle de doenças de plantas é o gengibre (Zingiber officinale Roscoe) (Almeida et al., 2017). Essa é uma planta aromática com aplicação nas indústrias alimentícias, cosmética e fitoterápica (Srinivasan, 2017). Pertence à família Zingiberaceae e apresenta em seu rizoma princípios ativos considerados antimicrobianos, como o gingerol, o zingibereno, além de compostos antioxidantes, dentre outros (Yeh et al., 2014). Embora derivados de gengibre possuam conhecido efeito benéfico na saúde humana (Švarc-Gajić et al., 2017), os potenciais efeitos e mecanismos relacionados à proteção de plantas ainda são pouco conhecidos.

A atividade biológica de derivados de plantas medicinais tem sido estudada em grande diversidade de espécies de plantas cultivadas. Entre essas espécies está o feijoeiro comum (Phaseolus vulgaris L.), que possui grande importância econômica e social, principalmente por seu destaque nutricional na alimentação humana e como alternativa de renda para agricultura familiar (Santos e Correa, 2011). No entanto, também é uma cultura com diversas doenças de importância, que inclui as causadas por fungos, bactérias, vírus e nematoides. Essas doenças podem limitar drasticamente a produção, exigindo estratégias de controle para evitar ou minimizar os danos à cultura (Wendland et al., 2016).

Buscando compreender possíveis mecanismos induzidos em plantas de feijoeiro por derivados de gengibre, este trabalho teve por objetivo avaliar a indução de mecanismos bioquímicos em feijoeiro pelo extrato aquoso e óleo essencial de gengibre.

\section{Material e Métodos}

Os experimentos foram conduzidos em laboratório e casa de vegetação na Universidade Federal da Fronteira Sul- UFFS, campus Laranjeiras do Sul - PR. Foram avaliados o óleo essencial e o extrato bruto aquoso de 
rizomas de gengibre. O óleo essencial foi obtido por arraste a vapor. Para utilização nos experimentos, foi diluído em Tween-20 a $0,1 \%$ para obtenção de diferentes concentrações. O extrato aquoso foi obtido pela trituração de rizomas frescos em liquidificador por 30 segundos, seguida de filtragem em gaze e papel de filtro. Para obtenção de extrato aquoso a $10 \%$, utilizouse a proporção de $10 \mathrm{~g}$ de rizomas em $100 \mathrm{~mL}$ de água destilada, e assim respectivamente para as demais concentrações.

Para avaliar o efeito de diferentes concentrações do óleo essencial e extrato aquoso de gengibre na indução de enzimas relacionadas à defesa vegetal, foi conduzido experimento em plântulas de feijoeiro. Para tanto, sementes de feijoeiro foram semeadas em bandejas de isopor com capacidade para 128 células contendo substrato comercial, e mantidas sob casa de vegetação. Foi utilizada uma plântula por célula, devidamente espaçadas para evitar contaminação entre parcelas. Quando as plântulas apresentavam as folhas primárias expandidas, foi realizada a aplicação dos tratamentos por aspersão até ponto de escorrimento. Após 72 horas da aplicação dos tratamentos, foi realizada a coleta de amostras para posterior análise bioquímica. Cada parcela foi representada por duas plântulas, sendo destas coletadas amostras de 0,5 g do tecido foliar, que, após a coleta, foram imediatamente congelados e mantidos a $-20^{\circ} \mathrm{C}$ para posterior extração e análise.

Em um segundo experimento foram avaliados os derivados de gengibre em diferentes horas após o tratamento. O experimento foi conduzido de forma semelhante ao anterior, porém, foram avaliadas as concentrações de $1 \%$ do óleo essencial e de $10 \%$ do extrato aquoso. A coleta das amostras para as análises bioquímicas foi realizada concomitantemente (tempo 0) e 24, 48, 72, 96 e 120 horas após os tratamentos.

Para avaliar o potencial efeito sistêmico dos derivados de gengibre, foi conduzido experimento em casa de vegetação em plantas de feijoeiro. Sementes de feijoeiro foram semeadas em vasos com capacidade de 2 L, contendo mistura de solo, areia e composto orgânico 2:1:1 (v/v). Após as plantas apresentarem dois trifólios completamente expandidos, foi realizada a aplicação dos tratamentos, por aspersão, no primeiro trifólio. Após 72 horas dos tratamentos foi realizada a amostragem de $0,5 \mathrm{~g}$ de tecido vegetal, tanto no trifólio tratado como no segundo trifólio (não tratado), sendo imediatamente congelados a $-20^{\circ} \mathrm{C}$ até o momento de realização das análises. Cada parcela foi representada por duas plantas. Constituíram tratamentos as concentrações de 0,1 e $1 \%$ do óleo essencial e de 1 e $10 \%$ do extrato aquoso.

Para realização das análises bioquímicas, as amostras de tecido foliar foram maceradas em $4 \mathrm{~mL}$ de tampão fosfato de sódio $0,01 \mathrm{M}(\mathrm{pH} 6,0)$ contendo $1 \%$ (p/p) de PVP (polivinilpirrolidona), em almofariz de porcelana. Os homogeneizados foram centrifugados a $14.500 \mathrm{~g}$ durante 20 minutos a $4^{\circ} \mathrm{C}$. O sobrenadante obtido foi utilizado para a determinação da atividade enzimática de peroxidases e polifenoloxidases. Todo o material empregado foi mantido sob refrigeração.

Para avaliação de peroxidases foi utilizada a metodologia proposta por Lusso e Pascholati (1999). A reação foi conduzida utilizando guaiacol como substrato (306 $\mu \mathrm{L}$ de peróxido de hidrogênio, 12,5 $\mathrm{mL}$ de guaiacol a $2 \%$ e $87,5 \mathrm{~mL}$ de tampão fosfato $0,01 \mathrm{M}(\mathrm{pH}$ $6,0)$, durante um minuto, a $30^{\circ} \mathrm{C}$. A leitura foi realizada em espectrofotômetro a $470 \mathrm{~nm}$. A atividade enzimática foi determinada pela variação ocorrida entre os valores situados na faixa de incremento linear. Os resultados foram expressos em variação de absorbância a $470 \mathrm{~nm}$ $\min ^{-1} \mathrm{~g}$ de tecido fresco ${ }^{-1}$.

Para avaliação de polifenoloxidases foi utilizada a metodologia proposta por Duangmal e Apenten (1999). O substrato para enzima foi composto por catecol na concentração de $20 \mathrm{mM}$, dissolvido em tampão fosfato de potássio $0,1 \mathrm{M}(\mathrm{pH} 6,8)$, mantendo-se o substrato à temperatura constante de $30^{\circ} \mathrm{C}$ em banho-maria. A reação foi conduzida misturando-se $900 \mu \mathrm{L}$ do substrato e $100 \mu \mathrm{L}$ do extrato enzimático, seguida de leituras em espectrofotômetro a $420 \mathrm{~nm}$. As leituras foram realizadas de forma direta, a cada 10 segundos, durante um minuto. Os resultados foram expressos em variação $\min ^{-1} \mathrm{~g}^{-1}$ tecido fresco.

A avaliação da fitoalexina faseolina foi realizada em hipocótilos de feijoeiro, segundo metodologia de Dixon et al. (1983), com modificações. Para obtenção dos hipocótilos, sementes de feijoeiro foram inicialmente desinfestadas em hipoclorito de sódio $0,5 \%$ por 2 minutos, seguida de lavagem em água destilada. Posteriormente, foi realizada a semeadura em areia esterilizada por autoclavagem e irrigadas com água destilada, mantidas em escuro a $25^{\circ} \mathrm{C}$ por oito dias. Após esse período, os hipocótilos com $5 \mathrm{~cm}$ foram destacados e transferidos para placas de Petri contendo papel de germinação estéril umedecido com água destilada. Foram utilizados cinco hipocótilos por placa, que consistiu em uma parcela experimental. Em seguida, foi realizada a aplicação dos tratamentos por aspersão sobre os hipocótilos até ponto de escorrimento, sendo mantidos em escuro a $25^{\circ} \mathrm{C}$. Após 48 horas, os hipocótilos foram transferidos para tubos de ensaio contendo $7 \mathrm{~mL}$ de álcool $70 \%$ e agitados por uma hora. Em seguida, foi realizada a determinação da absorbância em espectrofotômetro a $280 \mathrm{~nm}$.

Todos os experimentos foram conduzidos em delineamento inteiramente casualizado com quatro repetições. Em todos os experimentos foram avaliadas duas variedades de feijoeiro: Feijão Preto Tuiuiu e Feijão Carioca Pérola. Os resultados obtidos foram submetidos à análise de variância e, quando 
significativos ao nível de $5 \%$ de probabilidade, foram submetidos à análise de regressão com auxílio do programa Sisvar (Ferreira, 2007).

\section{Resultados e Discussão}

Para atividade de peroxidases, não foi observado efeito das concentrações de óleo essencial de gengibre sobre atividade dessa enzima nas folhas de feijoeiro (Figura 1A). Já o extrato aquoso promoveu efeito linear, mas somente no cultivar de feijão preto (Figura 1B). Esse resultado demonstra resposta diferencial entre as variedades estudadas e incremento na atividade com o aumento na concentração do extrato na variedade de feijão preto.

Em relação aos diferentes períodos de análise após a aplicação dos tratamentos, para as concentrações de óleo essencial (1\%) (Figura 2A) e extrato aquoso (10\%) (Figura 2B) foi observado aumento da atividade até certo ponto, e declínio posteriormente, atingindo ponto de máxima para feijão preto às 61,9 horas e para feijão carioca às 67,7 horas para o óleo essencial. Já para o extrato aquoso, os pontos de máxima foram 57,4 horas para o feijão preto e 71,2 horas para o feijão carioca, indicando que há incremento na atividade de peroxidase por esses derivados, mas que depois de determinado período ocorre redução.
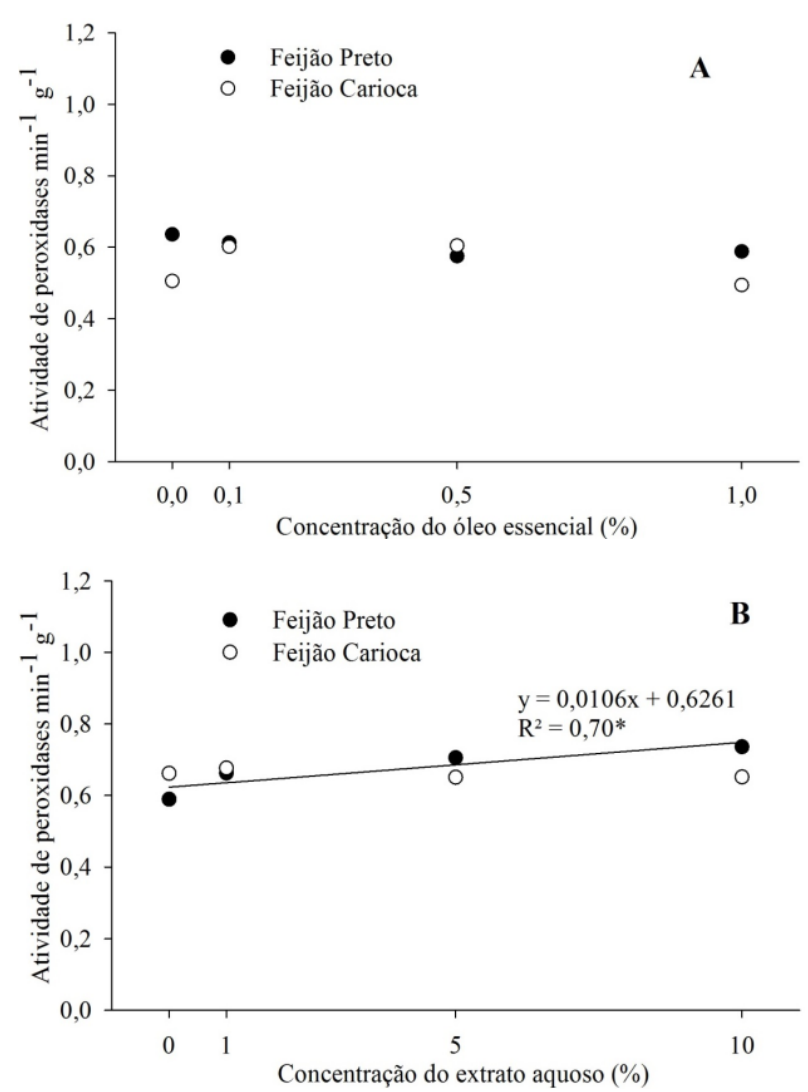

Figura 1. Atividade de peroxidases em folhas de feijoeiro tratadas com diferentes concentrações de óleo essencial (A) e extrato aquoso (B) de gengibre. *Significativo a $5 \%$ de probabilidade.
Rodrigues e Schwan-Estrada (2007) verificaram uma relação entre ativação de peroxidases e indução de resistência, visto que o tratamento com extrato de gengibre, além de proporcionar maior controle da doença, ocasionou aumento na atividade da enzima peroxidase nos tecidos das plantas de alface.

Cavalcanti et al. (2006) observaram que a resistência induzida em plantas de tomateiro pulverizadas com ASM e Ecolife $^{\circledR}$ foi evidenciada pelo aumento da atividade de peroxidases e polifenoloxidases, iniciado logo às primeiras horas após as pulverizações, continuando até 12 dias de avaliação. Resultados semelhantes foram encontrados, notando-se aumento da atividade da enzima após alguns dias, e posterior declínio.

Cavalcanti et al. (2006) ressaltam que plantas de tomateiro pulverizadas com ASM e Ecolife $^{\circledR}$, sem inoculação do patógeno da mancha bacteriana do tomate, mostraram aumento significativo na atividade de peroxidases em folhas a partir de 4 horas após pulverização em relação aos controles. Em plantas pulverizadas com Ecolife $\AA$, um marcante aumento da atividade de peroxidase, cerca de quatro vezes os respectivos controles, foi observado dentro do intervalo 8-24 após a pulverização, seguido de queda em 48 horas após a pulverização.
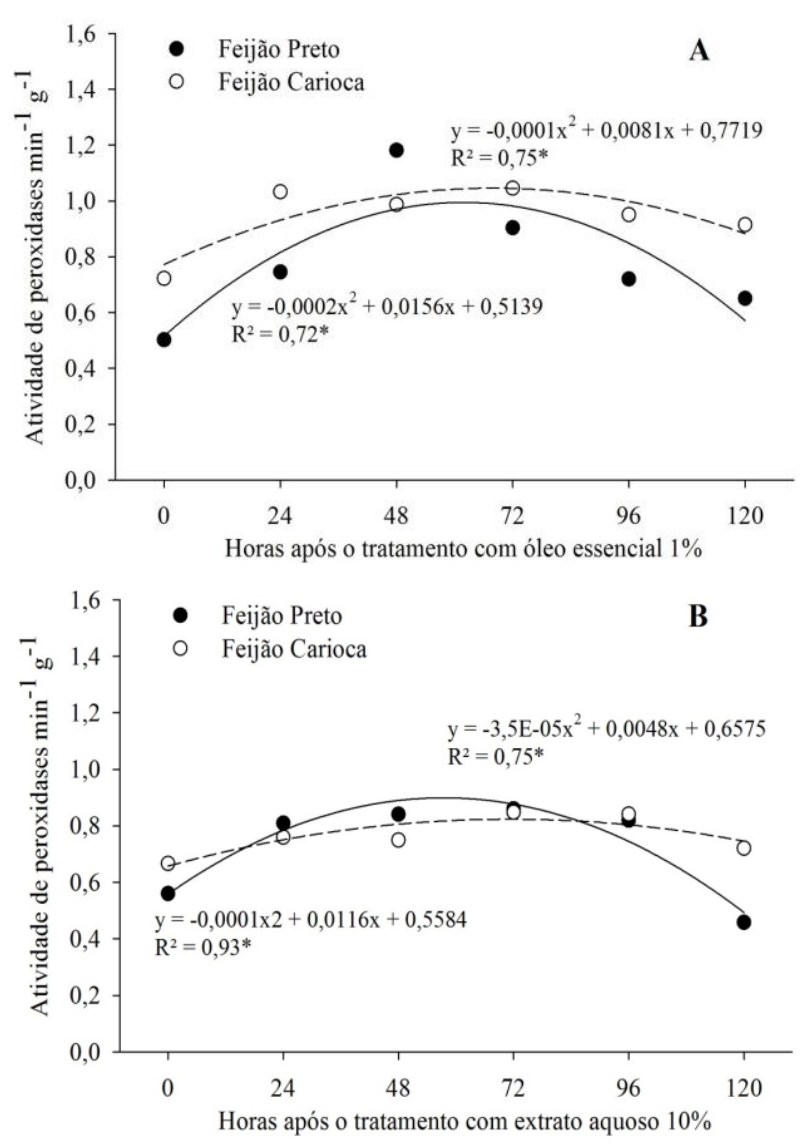

Figura 2. Atividade de peroxidases em folhas de feijoeiro tratadas com óleo essencial (A) e extrato aquoso (B) de gengibre em diferentes períodos após tratamento. *Significativo a $5 \%$ de probabilidade. 
Quanto à avaliação do potencial efeito local ou sistêmico do óleo essencial e do extrato aquoso, não foi observada diferença significativa entre os tratamentos e entre as folhas tratadas e não tratadas (Figura 3). Assim, os resultados obtidos não permitem evidenciar efeito sistêmico a partir desses derivados de gengibre em plantas de feijoeiro. É importante destacar que tanto no experimento com diferentes concentrações como no experimento para verificar potencial efeito sistêmico, a coleta das amostras foi realizada 72 horas após os tratamentos. É possível que a atividade de peroxidases estivesse em decréscimo, não sendo obtidos resultados mais expressivos.

Quanto à análise de polifenoloxidases, se observaram diferenças significativas quando tratadas com óleo essencial (Figura 4A). Em feijão carioca, houve aumento linear da atividade de polifenoloxidases pelo óleo essencial, indicando efeito dose-dependente; já para feijão preto houve tendência quadrática, com ponto de máxima atividade na concentração de $0,46 \%$ do óleo essencial. Para extrato aquoso não foram observadas diferenças significativas, independentemente da variedade avaliada (Figura 4B).

Esses resultados demonstram as respostas diferenciadas entre as variedades de feijoeiro, entre os derivados de gengibre e entre as enzimas avaliadas. É pertinente que o extrato aquoso e o óleo essencial de gengibre possam apresentar respostas diferenciais. $\mathrm{O}$ extrato aquoso obtido por trituração tende a possuir composição complexa de substâncias solúveis em água. Já o óleo essencial é representado por compostos voláteis, sendo que em gengibre tem sido relatado o predomínio de sequiterpenos, como a-zingibereno (Srinivasan, 2017).

Segundo estudos de Campos et al. (2004), a atividade da polifenoloxidase foi significativamente maior nas plantas de feijão tratadas com ácido salicílico e fungo indutor (Colletotrichum lindemuthianum); o cultivar de feijão resistente apresentou maior atividade desta enzima dentre os cultivares resistentes e susceptíveis testados. No mesmo estudo, a atividade de peroxidase mostrou resultado semelhante à polifeniloxidase.

Tanto as peroxidases como as polifenoloxidases lideram a degradação oxidativa de compostos fenólicos como mecanismo de defesa vegetal (Barros et al., 2010), sendo importantes no processo de indução de resistência em plantas.

Em relação à análise em diferentes períodos após a realização dos tratamentos, foi observado aumento linear na atividade de polifenoloxidases somente quando tratadas com óleo essencial (Figura 5A), não sendo observado aumento com extrato aquoso (Figura 5B).

Esse resultado reforça o obtido no experimento com as diferentes concentrações, onde também não foi observado efeito significativo de polifenoloxidases pelo extrato aquoso, mas sim pelo óleo essencial.

$O$ efeito linear observado na atividade de polifenoloxidases pelo óleo essencial até 120 horas após o tratamento demonstra o potencial efeito indutor mais persistente dessa enzima, que pode ultrapassar cinco dias, enquanto que para peroxidases o efeito indutor teve redução após três dias dos tratamentos. Efeito na atividade de polifenoloxidases até 120 horas após tratamento foi observado também por Lorenzetti et al. (2018) em plantas de soja tratadas com extrato de alecrim (Rosmarinus officinalis L.) a 5\%.

Quanto à avaliação do potencial efeito local ou sistêmico do extrato e óleo essencial, não foi observada diferença significativa entre folhas tratadas e não tratadas (Figura 6). De forma semelhante ao observado para peroxidases, não foi possível evidenciar efeito sistêmico pelos derivados, embora a possibilidade de efeito sistêmico pelo extrato e óleo essencial de gengibre não possam ser também descartados, uma vez que não foi observada diferença significativa entre os tratamentos e concentrações utilizados nesse experimento.

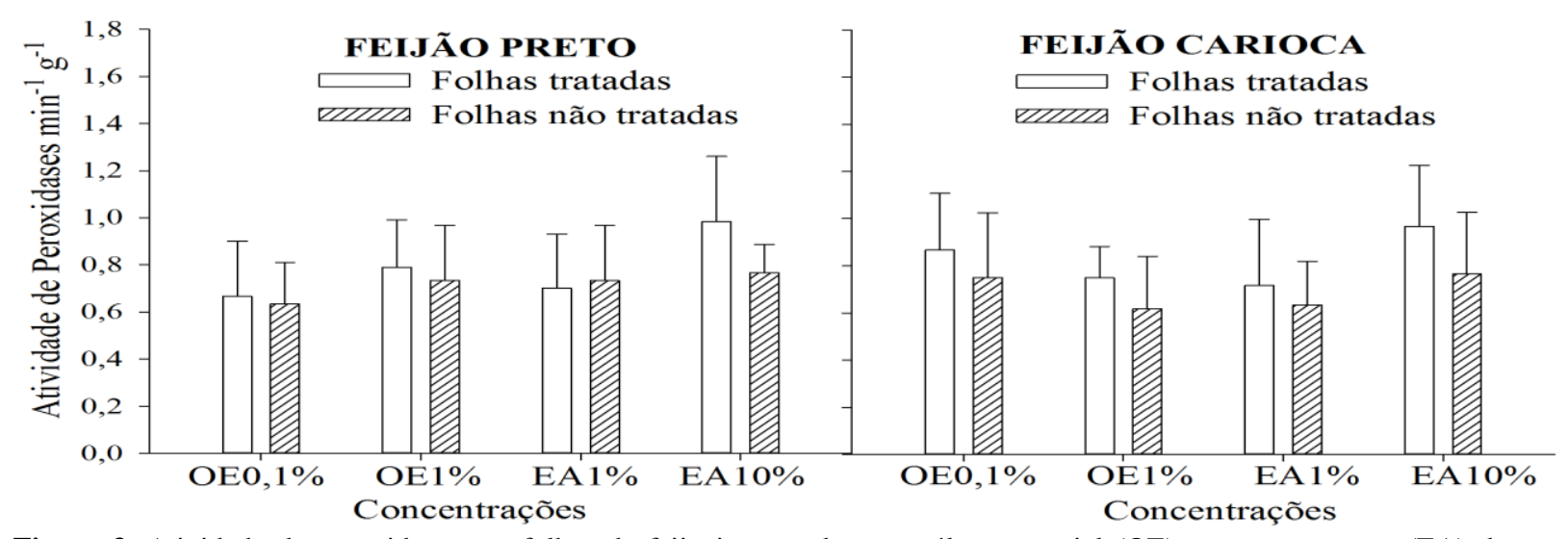

Figura 3. Atividade de peroxidases em folhas de feijoeiro tratadas com óleo essencial (OE) e extrato aquoso (EA) de gengibre comparadas com folhas não tratadas. 

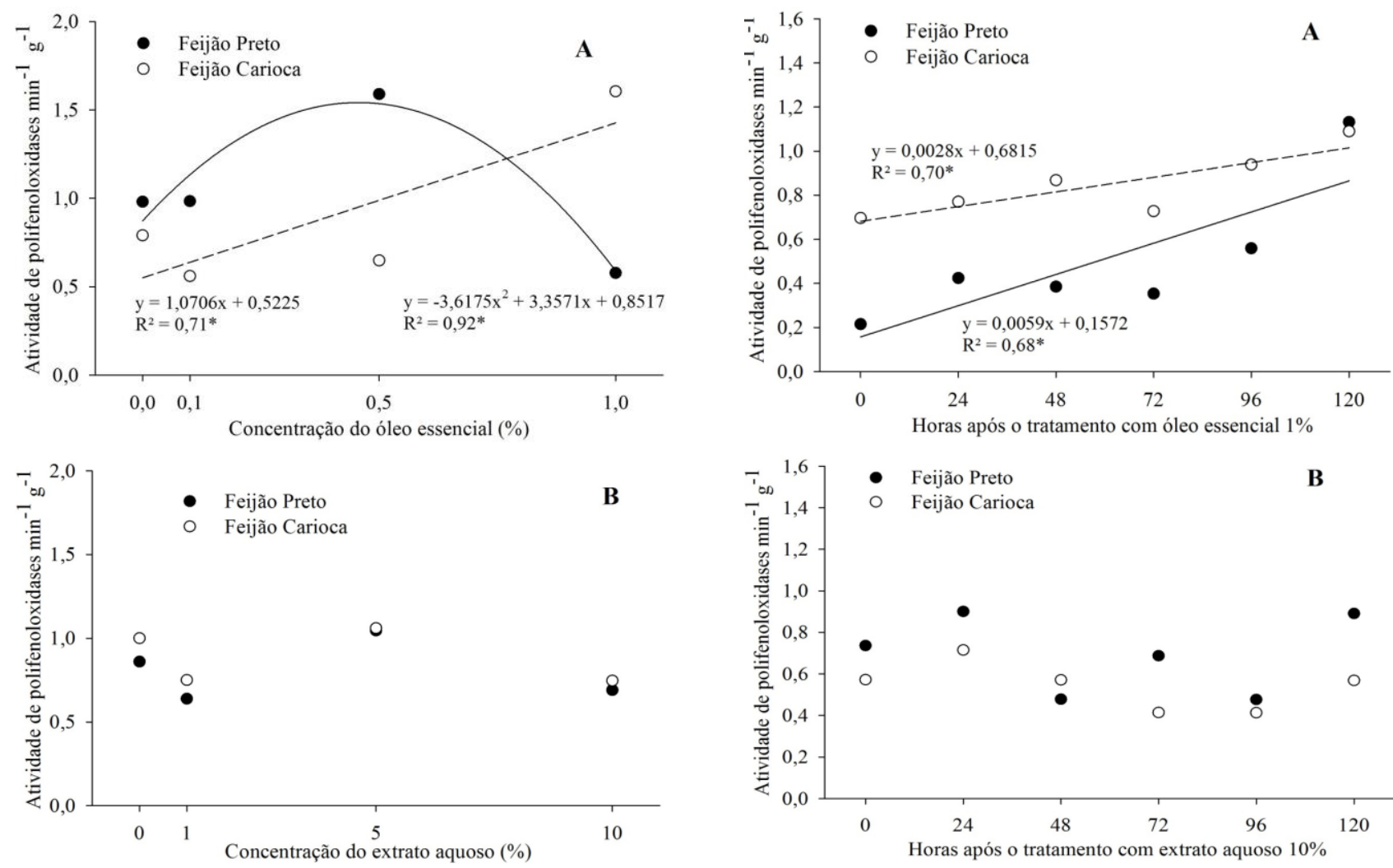

Figura 4. Atividade de polifenoloxidases em folhas de feijoeiro tratadas com diferentes concentrações do óleo essencial (A) e extrato aquoso (B) de gengibre. *Significativo a $5 \%$ de probabilidade.

Figura 5. Atividade de polifenoloxidases em folhas de feijoeiro tratadas com óleo essencial (A) extrato aquoso (B) de gengibre em diferentes períodos após tratamento. *Significativo a $5 \%$ de probabilidade.
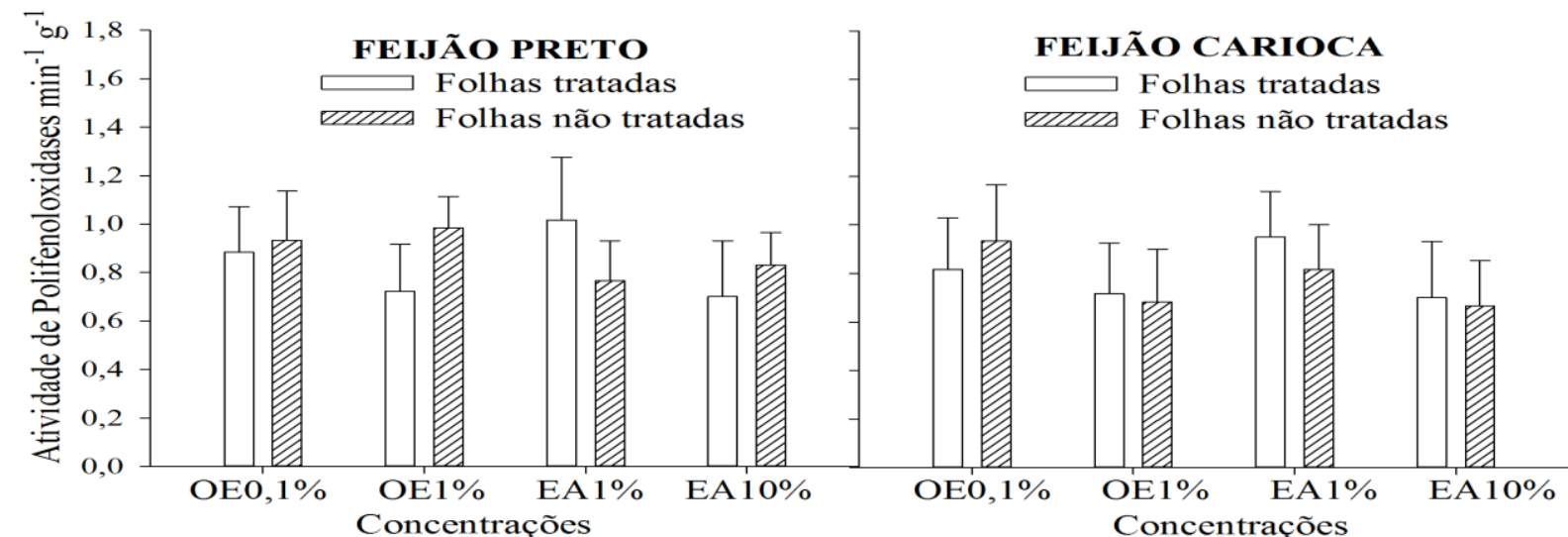

Figura 6. Atividade de polifenoloxidases em folhas de feijoeiro tratadas com óleo essencial (OE) e extrato aquoso (EA) de gengibre comparadas com folhas não tratadas.

Outros estudos têm relatado indução de polifenoloxidases em folhas não tratadas de feijoeiro. No trabalho desenvolvido por Viecelli et al. (2009), foi observado que a atividade da polifenoloxidase foi influenciada pelos tratamentos com filtrado de cultura de $P$. sanguineus em feijoeiro, na terceira folha tratada, bem como na quarta folha não tratada e inoculada, demonstrando a sistemicidade do efeito; no experimento não se constatou efeito diferencial entre as folhas com e sem inoculação.
Quanto ao acúmulo da fitoalexina faseolina em hipocótilos de feijoeiro, foi observado incremento linear em ambas as variedades de feijoeiro quando utilizadas diferentes concentrações do óleo essencial de gengibre (Figura 7A). Quando utilizado o extrato aquoso, houve aumento linear apenas para variedade de feijão preto (Figura 7B). Os resultados indicam o efeito indutor dessa fitoalexina em feijoeiro, tanto pelo óleo essencial como pelo extrato, embora possa haver resposta diferencial entre as variedades. 
Grande parte das pesquisas envolvendo a relação entre fitoalexinas e a indução de resistência em plantas tem sido realizada com deoxiantocianidinas em sorgo e gliceolina em soja. Esses trabalhos têm demonstrado a importância das fitoalexinas nas respostas de defesa da planta a fitopatógenos. Em diversas outras culturas também têm sido relacionado o acúmulo de fitoalexinas com a defesa vegetal (Ahuja et al., 2012).

Em feijoeiro, alguns outros derivados vegetais já demonstraram efeito na indução de fitoalexina. Para o acúmulo de faseolina em hipocótilos de feijoeiro tratados com extrato aquoso de alho e alecrim, Brand et al. (2010) constataram que todas as concentrações utilizadas (0,5 a 3\%) de ambas as espécies promoveram acúmulo de faseolina superior ao tratamento testemunha.

Além de extratos e óleos essenciais, outros derivados de plantas também já foram relatados com potencial em induzir fitoalexinas em plantas, como no caso de hidrolatos (Moura et al., 2014), sendo um importante indicativo do potencial indutor de resistência. A indução de enzimas como peroxidases e polifenoloxidases, bem como de fitoalexinas em plantas, tanto por agentes bióticos quanto por abióticos, representa que importantes respostas de defesa da planta estão sendo ativadas (Oliveira et al., 2016).
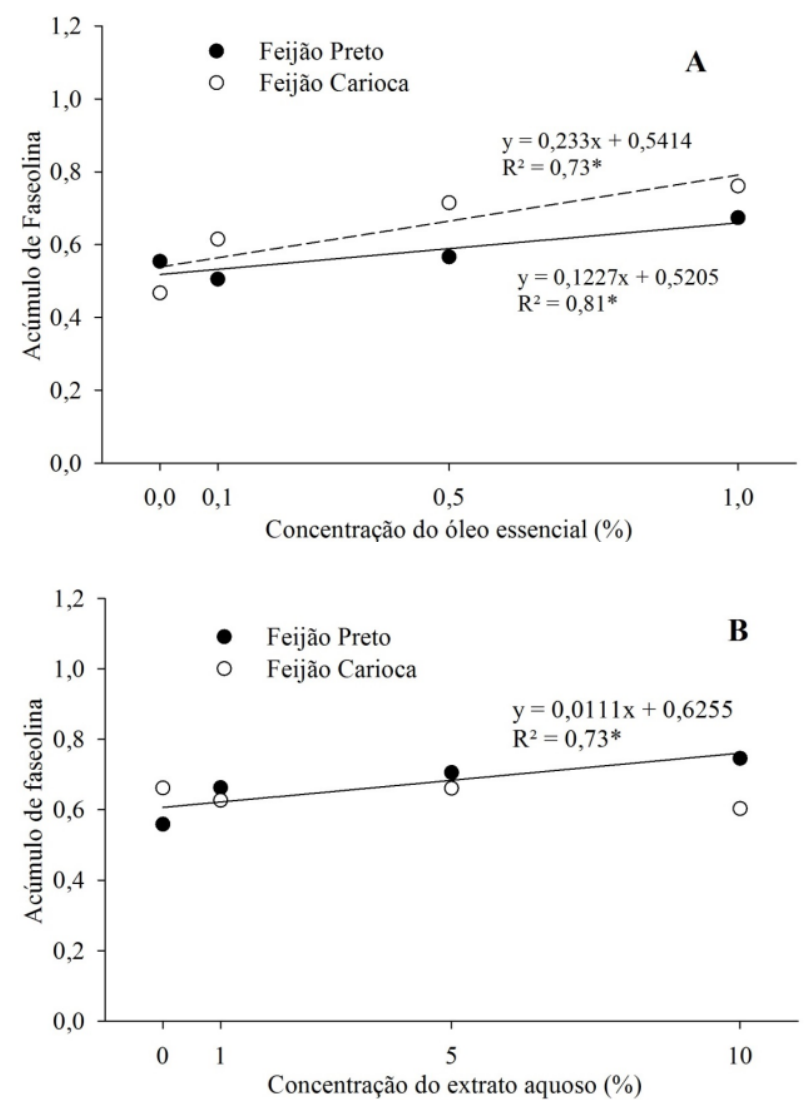

Figura 7. Acúmulo de faseolina em cotilédones de feijoeiro tratados com diferentes concentrações de óleo essencial (A) e extrato aquoso (B) de gengibre. *Significativo a 5\% de probabilidade.

\section{Conclusões}

O óleo essencial e extrato aquoso promoveram indução de peroxidases com efeito quadrático ao longo do tempo, embora efeito das diferentes concentrações tenha sido observado somente em feijão preto. Somente o óleo essencial promoveu indução de polifenoloxidases. O óleo essencial e extrato aquoso promoveram indução de faseolina em hipocótilos de feijoeiro.

Não foi observado efeito sistêmico em plantas de feijoeiro pelos derivados avaliados.

Houve efeito diferencial entre as variedades de feijoeiro utilizadas para alguns atributos avaliados.

\section{Referências Bibliográficas}

Ahuja, I., Kissen, R., Bones, A.M., 2012. Phytoalexins in defense against pathogens. Trends in plant science, 17, 73-90.

Almeida, E.N., Moura, G.S., Franzener, G., 2017 Potenciais alternativas com extratos vegetais no controle da pinta preta do tomateiro. Revista Verde de Agroecologia e Desenvolvimento Sustentável, 12, 687-694.

Barros, F.C., Sagata, É., Ferreira, L.C.C., Juliatti, F.C., 2010. Indução de resistência em plantas contra fitopatógenos. Bioscience Journal, 26, 231-239.

Bizzo, H.R., Hovell, A.M.C., Rezende, C.M., 2009. Óleos essenciais no Brasil: aspectos gerais, desenvolvimento e perspectivas. Química Nova, 32, 588-594.

Brand, S.C., Blume, E., Muniz, M.F.B., Milanesi, P.M., Scheren, M.B., Antonello, L.M., 2010. Extratos de alho e alecrim na indução de faseolina em feijoeiro e fungitoxicidade sobre Colletotrichum lindemuthianum. Ciência Rural, 40, 1881-1887.

Campos, A., Ferreira, A.G., Hampe, M.M.V., Antunes, I.F., Brancão, N., Silveira, E.P., Osório, V.A., Augustin, E., 2004. Atividade de peroxidase e polifenoloxidase na resistência do feijão à antracnose. Pesquisa Agropecuária Brasileira, 39, 637 643.

Cavalcanti, F.R., Resende, M.L.V., Zacaroni, A.B., Ribeiro Junior, P.M., Costa, J.C.B. \& Souza, R.M., 2006. AcibenzolarS-metil e Ecolife ${ }^{\circledR}$ na indução de respostas de defesa do tomateiro contra a mancha bacteriana (Xanthomonas vesicatoria). Fitopatologia Brasileira, 31, 372-380.

Dixon, R.A., Dey, P.M., Lawton, M.A., Lamb, C.J., 1983. Phytoalexin indution in french bean: intercellular transmission of elicitation in cell suspension cultures and hypocotyl sections of Phaseolus vulgaris. Plant Physiology, 71, 251-256.

Duangmal, K., Apenten, R.K.O., 1999. A comparative study of poliphenoloxidases from taro (Colocasia esculenta) and potato (Solanum tuberosum var. Romano). Food Chemistry, $64,351-359$

Ferreira, D.F., 2007. Sisvar: Sistema de análise de variância para dados balanceados, versão 5.0. Lavras-MG: DEX/UFLA, CD-ROM. Software. 
Franzener, G., Schwan-Estrada, K.R.F., Moura, G.S., Kuhn, O.J., Stangarlin, J.R., 2018. Induction of defense enzymes and control of anthracnose in cucumber by Corymbia citriodora aqueous extract. Summa Phytopathologica, 44, 10-16.

Lorenzetti, E., Stangarlin, J.R., Kuhn, O.J., Portz, R.L., 2018. Indução de resistência à Macrophomina phaseolina em soja tratada com extrato de alecrim. Summa Phytopathologica, 44, 45-50.

Lusso, M.F.G., Pascholati, S.F., 1999. Activity and isoenzymatic pattern of soluble peroxidades in maize tissues after mechanical injury or fungal inoculation. Summa Phytophatologica, 25, 244-249.

Morais, L.A.S., 2009. Influência dos fatores abióticos na composição química dos óleos essenciais. Horticultura Brasileira, 27, 4050-4063.

Moura, G.S., Franzener, G., Stangarlin, J.R., Schwan-Estrada, K.R.F., 2014. Atividade antimicrobiana e indutora de fitoalexinas do hidrolato de carqueja [Baccharis trimera (Less.) DC.]. Revista Brasileira de Plantas Medicinais, 16 309-315.

Oliveira, M.D.M., Varanda, C.M.R., Félix, M.R.F., 2016. Induced resistance during the interaction pathogen $\mathrm{x}$ plant and the use of resistance inducers. Phytochemistry Letters, 15, 152-158.

Ootani, M.A., Aguiar, R.W., Ramos, A.C.C., Brito, D.R., Silva, J.B., Cajazeira, J.P., 2013. Use of essential oils in agriculture. Journal of Biotechnology and Biodiversity, 4, 162-175.

Raven, P.H., Eichhorn, S.E., Evert, R.F., 2014. Biologia Vegetal, oitava ed. Rio de Janeiro-RJ, Guanabara Koogan.

Rodrigues, E., Schwan-Estrada, K.R.F., 2007. Fungitoxicidade, atividade elicitora de fitoalexinas e proteção de alface em sistema de cultivo orgânico contra Sclerotinia sclerotiorum pelo extrato de gengibre. Summa Phytopathologica, 33, 124-128.

Santos, A., Correa, A., 2011. Desempenho agronômico de genótipos de feijão comum cultivados no período "da seca" em Aquidauana-MS. Revista Agrarian, 4, 33-42.

Sbalcheiro, C.C., Denardin, N.D., Brammer, S.P., 2009. Alterações de isoenzimas peroxidases em plantas de feijoeiro tratadas com biocontrolador do crestamento bacteriano comum. Tropical Plant Pathology, 34, 29-37.

Schwan-Estrada, K.R.F., 2009. Extratos vegetais e de cogumelos no controle de doenças de plantas. Horticultura Brasileira, 27, 4038-4045.

Srinivasan, K., 2017. Ginger rhizomes (Zingiber officinale): A spice with multiple health beneficial potentials. PharmaNutrition, 5, 18-28.

Švarc-Gajić, J., Cvetanović, A., Segura-Carretero, A., Linares, I.B., Mašković, P., 2017. Characterisation of ginger extracts obtained by subcritical water. Journal of Supercritical Fluids, 123, 92-100.

Viecelli, C.A., Stangarlin, J.R., Kuhn, O.J., Schwan-, K.R.F., 2009. Indução de resistência em feijoeiro por filtrado de cultura de Pycnoporus sanguineus contra Pseudocercospora griseola. Tropical Plant Pathology, 34, 87-96.

Yeh, H.Y., Chuang, C.H., Chen, H.C., Wan, C.J., Chen, T.L., Lin, L.Y., 2014. Bioactive components analysis of two various gingers (Zingiber officinale Roscoe) and antioxidant effect of ginger extracts. LWT - Food Science and Technology, 55, 329-334.

Wendland, A., Moreira, A.S., Bianchini, A., Giampan, J.S., Lobo Jr., M., 2016. Doenças Do Feijoeiro, in: Amorim, L., Rezende, J.A.M., Bergamin Filho, A., Camargo, L.E.A. Manual de Fitopatologia: Doenças das Plantas Cultivadas, quinta ed. Ouro Fino, Ceres, p. 383-396. 